\title{
Article \\ Effect of Atomoxetine on Behavioral Difficulties and Growth Development of Primary School Children with Attention-Deficit/Hyperactivity Disorder: A Prospective Study
}

\author{
Huiya Mei ${ }^{1}$, Ruijin Xie ${ }^{1}$, Tianxiao Li ${ }^{1}$, Zongxin Chen ${ }^{2}$, Yueying Liu ${ }^{1, *(1)}$ and Chenyu Sun ${ }^{3, *(1)}$ \\ 1 Department of Pediatrics, Affiliated Hospital of Jiangnan University, No. 1000, Hefeng Avenue, \\ Wuxi 214122, China; 6212809027@stu.jiangnan.edu.cn (H.M.); 6202809028@stu.jiangnan.edu.cn (R.X.); \\ 6192807008@stu.jiangnan.edu.cn (T.L.) \\ 2 The First Affiliated Hospital of Soochow University, No. 188, Shixin Avenue, Suzhou 215000, China; \\ sdfyyczx@163.com \\ 3 AMITA Health Saint Joseph Hospital Chicago, 2900 N. Lake Shore Drive, Chicago, IL 60657, USA \\ * Correspondence: shadow7671@163.com (Y.L.); drsunchenyu@yeah.net (C.S.)
}

Citation: Mei, H.; Xie, R.; Li, T.; Chen, Z.; Liu, Y.; Sun, C. Effect of Atomoxetine on Behavioral Difficulties and Growth Development of Primary School Children with Attention-Deficit/Hyperactivity Disorder: A Prospective Study. Children 2022, 9, 212. https:// doi.org/10.3390/children9020212

Received: 4 January 2022

Accepted: 4 February 2022

Published: 6 February 2022

Publisher's Note: MDPI stays neutral with regard to jurisdictional claims in published maps and institutional affiliations.

Copyright: (C) 2022 by the authors. Licensee MDPI, Basel, Switzerland. This article is an open access article distributed under the terms and conditions of the Creative Commons Attribution (CC BY) license (https:// creativecommons.org/licenses/by/ $4.0 /$ ).
Abstract: (1) Objective: Atomoxetine is a selective norepinephrine reuptake inhibitor used to treat attention-deficit/hyperactivity disorder (ADHD) in children over six years old. Although it is common knowledge that primary school children with ADHD often present with difficulties in the morning prior to school and in the evening, these two periods, and the family interactions they involve, are often neglected in studies of ADHD. Questionnaire-Children with Difficulties (QCD) has been widely used in China to evaluate parents' perceptions of ADHD and patients' daily behaviors during different times. In the long term, the efficacy and safety of atomoxetine have been well established in previous studies. Still, the short-term effects of atomoxetine treatment on serum growth parameters, such as IGF-1, IGFBP-3, and thyroid function, are not well documented. Therefore, this study was the first one using the QCD to quantify the efficacy of atomoxetine treatment in the morning prior to school and in the evening, and has investigated the possible influence on the growth parameters of Chinese primary school children with ADHD. (2) Method: This prospective study was conducted at the Department of Pediatrics at the Affiliated Hospital of Jiangnan University from August 2019 to February 2021. Changes in the children's behavior and core ADHD symptoms following treatment were assessed using three parent-reported questionnaires, including Children with Difficulties (QCD), the Swanson, Nolan, and Pelham IV scale (SNAP-IV), and the Conners' parents rating scales (CPRS). The height, weight, and body mass index (BMI) were measured and corrected to reflect the standard deviations (SDS) in Chinese children based on age and gender. Serum growth parameters, such as insulin-like growth factor 1 (IGF-1), insulin-like growth factorbinding protein 3 (IGFBP-3), and thyroid function, were also measured to assess the children's growth development. Any adverse drug reactions were assessed every three weeks. (3) Result: Finally, 149 children were enrolled in this study, and they completed 12 weeks of atomoxetine treatment. The QCD results indicated that the atomoxetine treatment could significantly alleviate behavioral difficulties in primary children with ADHD, especially in the morning prior to school $(p<0.001, r=0.66)$ and in the evening $(p<0.001, r=0.73)$. A statically significant decrease in weight SDS $(p<0.05)$ was noted during treatment, but the effect size was slight $(r=0.09)$. The atomoxetine treatment had no significant impact on height SDS, BMI SDS, and serum growth parameters, such as the levels of IGF-1, IGFBP-3, and thyroid function. The SNAP-IV results showed a significant improvement in the core symptoms of ADHD, while the CPRS results indicated a significant improvement in controlling ADHD symptoms across two different domains, learning problems $(r=0.81)$ and hyperactivity $(r=0.86)$. No severe adverse reactions were observed in the course of treatment, and the most common adverse reactions were gastrointestinal symptoms. (4) Conclusions: Atomoxetine is an effective and safe treatment for primary school children with ADHD. In China, it may be an excellent choice to alleviate parenting stress and improve the condition of primary school children with ADHD. Moreover, our study indicated that the serum levels of IGF-1 and IGFBP-3 were within the normal range in newly diagnosed ADHD children, and atomoxetine 
will not affect the serum concentration of growth parameters, such as IGF-1, IGFBP-3, and thyroid function, in the short term. However, the treatment may reduce appetite, resulting in a reduction in the Children's weight for a short period. Further observational studies to monitor the long-term effects of atomoxetine on primary school children are recommended.

Keywords: ADHD; atomoxetine; insulin-like growth factor 1; behavioral difficulties; growth development

\section{Introduction}

Attention-deficit/hyperactivity disorder (ADHD) is the most common childhood neurodevelopmental disorder, with a prevalence of approximately $5 \%$ worldwide [1]. It is defined as a persistent pattern of inattention, hyperactivity, and impulsivity that significantly impedes children's academic and social development [1-3]. If left untreated, ADHD may cause long-term morbidity and poor quality of life in adulthood [2]. Therefore, school-aged children with ADHD must receive essential medical treatment.

Behavioral and psychosocial treatments (BPT) are the recommended nonpharmacological treatments to alleviate core the symptoms of ADHD, and they are the first-line treatments for very young children $(<5$ years old) [4,5]. However, the efficiency of BPT remains questionable, with controversial evidence and conclusions in previous studies [5]. Pharmacological treatment is still widely used as ADHD treatment in most clinical practices and guidelines [6-8]. The current standard pharmacological treatment for primary school children with ADHD involves using stimulants or non-stimulants that regulate catecholamines [3]. In China, methylphenidate is widely used as a central nervous system stimulant, while atomoxetine is used as a non-stimulant. Atomoxetine was the first non-stimulant medication approved by the United States Food and Drug Administration (FDA) to treat ADHD patients aged over six years [9]. Methylphenidate is a short-acting stimulant that is well tolerated in the short term. It reduces height and weight in the long term $[10,11]$, while the short-term effects of atomoxetine on growth development are not well documented. Long-term atomoxetine treatment may be associated with deficits in height growth [10]. In addition, some studies have indicated that atomoxetine might have additional side effects beyond norepinephrine reuptake inhibition. Hence, the safety and efficacy of this treatment require further investigation [11,12]. Therefore, this study was conducted to investigate the short-term adverse effects of atomoxetine, and its potential impacts on height and weight changes in primary school children.

Studies performed during the last decade indicate that the development of ADHD involves a complex interaction of the neurobiological and neurochemical systems. However, the precise etiology and pathophysiology behind this disease are still not fully understood $[8,13,14]$. Neurotrophins, which include brain-derived neurotrophic factor (BDNF), nerve growth factor (NGF), and insulin-like growth factor-1 (IGF-1), are a family of proteins that regulate neural growth, survival, and differentiation $[15,16]$. Recently, animal and clinical studies have indicated that the brain-derived neurotrophic factors involved the pathophysiology of ADHD and could be potential biomarkers [17,18]. IGF-1 is one of the more frequently investigated neurotrophins. It is the principal mediator of growth hormone $(\mathrm{GH})$, and plays a critical role in regulating both anabolic and catabolic pathways in skeletal muscle, and in promoting bone formation and growth [19,20]. In addition, the IGF-1/IGFBP-3 axis was considered to be a potential biochemical growth maturity indicator, especially in children [21-24]. Previous studies applied IGF-1, IGFBP-3, and thyroid function tests as growth parameters to quantify the effects of methylphenidate on children's growth development [25-27]. However, few studies have explored the impact of atomoxetine on children's growth development according to these three growth parameters. Hence, this study investigated the changes in serum IGF-1, IGFBP-3 levels, thyroid 
function, total protein (TP), albumin (ALB), and hemoglobin (HGB) to quantify the effects of atomoxetine on children's growth development in the short term.

Although it is well known that primary school children with ADHD often present with difficulties in the morning prior to school and in the evening, these two periods, and the family interactions that they entail, are often neglected in studies of ADHD [28,29]. A novel phase III delayed release and extended release methylphenidate (HLD200) was designed to provide an extended duration of release from the morning prior to school, throughout the day, and into the evening [28,30-32]. Kelsey et al.'s study indicated that a once-daily administration of atomoxetine in the morning provided safe, rapid, and continuous symptom relief throughout the day [33]. However, information about the effects of atomoxetine on different periods of the day is limited. Questionnaire-Children with Difficulties (QCD) has been widely used in China to evaluate parents' perceptions of ADHD and patients' daily behaviors during different times of the day, such as in the morning, during school, after school, in the evening, and at night time [34,35]. Therefore, this study first used the QCD to quantify the efficacy of atomoxetine treatment in improving behavioral difficulties at different times.

\section{Materials and Methods}

\subsection{Data Collection}

This prospective study was conducted at the Department of Pediatrics at the Affiliated Hospital of Jiangnan University from August 2019 to February 2021. The criteria for study inclusion were: (1) aged between 6 and 12 years; (2) newly diagnosed ADHD patients; (3) met the ADHD diagnostic criteria via clinical assessment according to the Diagnostic and Statistical Manual of Mental Disorders, Fifth Edition (DSM-V); (4) received a 12-week treatment with atomoxetine for the first time. Patients with developmentally induced growth suppression disorders, congenital malformations, or chronic somatic diseases, such as asthma, arthritis, and chronic back/neck pain, were excluded from the study. Patients suffering from neural disorders (including epilepsy, cerebral palsy, or developmental delay) and acute diseases at the time of admission (including upper respiratory tract infection and enteritis) were also excluded. Patients who received previous pharmacological treatment with either atomoxetine or methylphenidate, or others, were not included. The workflow used to screen for eligible participants is illustrated in Figure 1.

\subsection{Ethical Considerations}

The guardians or parents of the patients participating in the study provided written informed consent for us to obtain anonymous data from the children's medical records at the very beginning. They were also fully informed that thyroid function, serum IGF-1, and IGFBP-3 levels were measured for the clinical assessment of growth development and for the purpose of clinical research. The Research Ethics Committees of the Affiliated Hospital of Jiangnan University (Wuxi, China) approved the study (No.LS2019047).

\subsection{Treatment}

The children received pharmacologic therapy as indicated by the second edition of the Chinese ADHD guidelines, released in 2015 [36]. Atomoxetine (Eli Lilly and Company, Indianapolis, IN, USA) was administered orally once daily (d) using an initial dose of $0.5 \mathrm{mg} / \mathrm{kg} / \mathrm{d}$. The amount was gradually increased up to a maximum of $1.2 \mathrm{mg} / \mathrm{kg} / \mathrm{d}$ according to the tolerance of the drug and the improvement of core symptoms. Once symptom control was achieved, the dose was maintained throughout the treatment. 


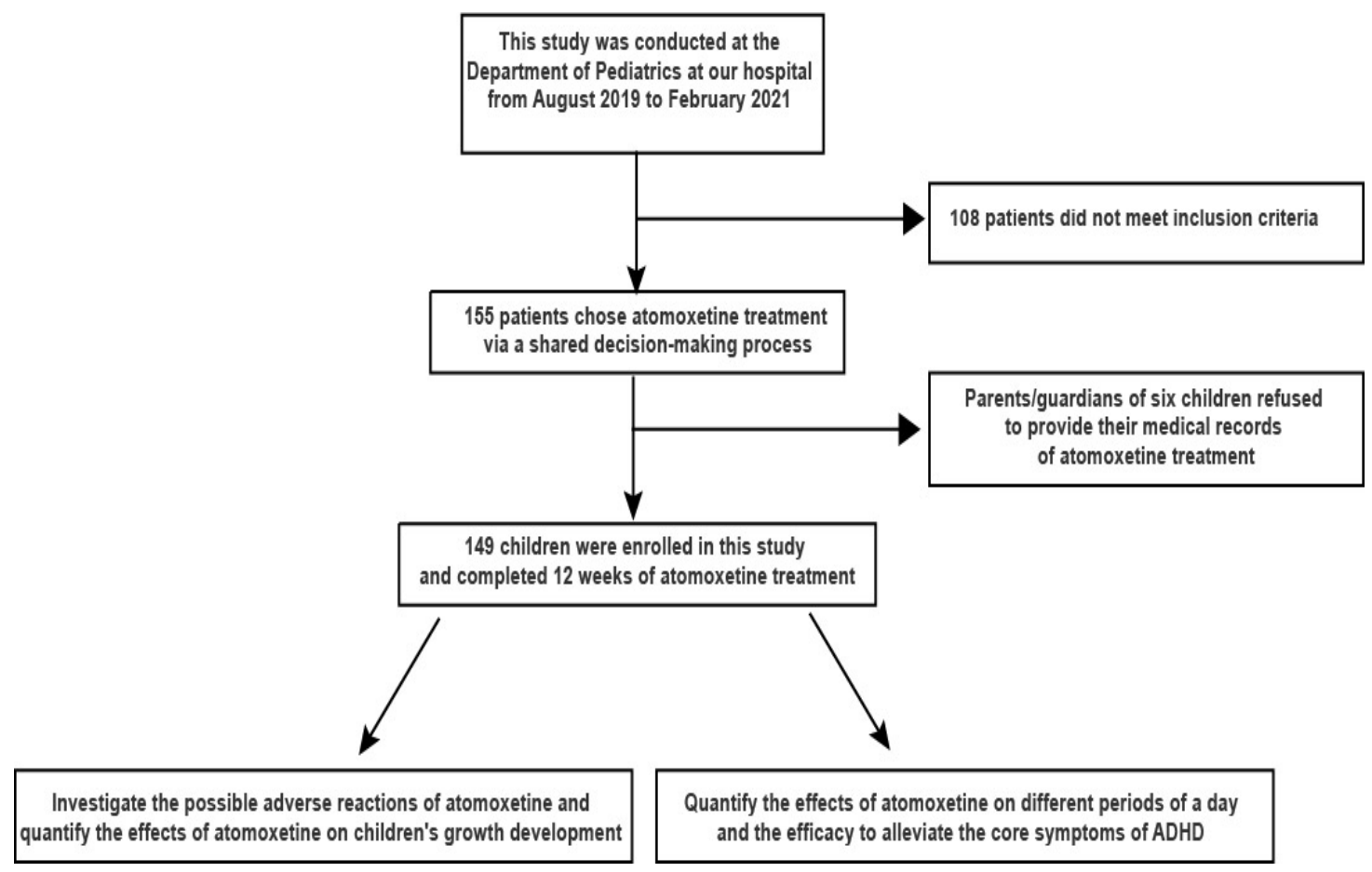

Figure 1. Flow chart of the study.

\subsection{Questionnaires}

To quantify the effects of atomoxetine at different periods of a day, and its efficacy at alleviating the core symptoms of ADHD, an inventory of the improvement in the children's behavior and core symptoms of ADHD was kept by using three parent-reported questionnaires, completed electronically, including the Chinese version of the QuestionnaireChildren with Difficulties (QCD), the Chinese version of the Swanson, Nolan, and Pelham IV scale (SNAP-IV), and the Conners' Parents Rating Scales (CPRS). The QCD scale consists of 20 questions that focus on the difficulties faced by children with ADHD before going to school (Q 1 4), during school (Q 5 7), after school (Q 8 10), in the evening (Q 11 14), and at night (Q 15 18), and on their overall behavior (Q 19 20). Four different level scores were used: 0 means disagree, 1 means partially agree, 2 means mostly agree, and 3 means complete agree. This questionnaire is a reliable and valid tool with which to assess daily ADHD symptoms in various Chinese studies [35,37]. SNAP-IV is based on the DSM-5 criteria for ADHD, and the Chinese SNAP-IV can accurately assess three presentation specifiers (inattention, hyperactivity/impulsivity, and oppositional), as can its English version [38]. This tool is widely used to evaluate the effectiveness of ADHD treatments, and was found to be a reliable and well-validated instrument in previous studies [39,40]. CPRS is a parent-reported tool used to quantitatively measure specific behavioral, social, and academic issues in children aged between 6 and 18 years [41]. This tool is also commonly used to diagnose ADHD, and assesses the impact of ADHD symptoms on the children's academic performance, behavior, quality of life, and relationships [42,43].

\subsection{Adverse Reactions and Serum Analysis}

To investigate the possible adverse reactions to atomoxetine, an adapted semi-structured interview was recorded every three weeks by the guardians or parents electronically (Supplementary File S1: Detailed information on the semi-structured interview) based on the literature [44-46]. In this study, we focused on the most common drug adverse reactions, such as severe adverse reactions (headache, insomnia, suicide attempt) and gastrointestinal symptoms (loss of appetite, constipation, vomiting), fatigue, dizziness, and emotional instability) $[47,48]$. To quantify the effects of atomoxetine on children's 
growth development in the short term, thyroid function, TP, ALP, and HGB levels were measured pre-treatment and post-treatment. The serum levels of IGF-1 and IGFBP-3 was also measured via the chemiluminescent immunometric assay (CLIA) method and analyzed in our hospital's laboratory [49].

\subsection{Statistical Analyses}

Statistical analyses were performed using the Statistical Package for the Social Sciences (SPSS) software version 23.0 (IBM Corporation, Armonk, NY, USA). The results were presented as means \pm standard deviations. The pre-treatment and post-treatment variables were compared using a paired $t$-test. For all tests, a $p$-value below 0.05 was considered to be statistically significant.

\section{Results}

\subsection{Demographics}

A total of 155 patients chose atomoxetine treatment via a shared decision-making process, with input from the physician and the guardians or parents. The parents/guardians of six children refused to provide their medical records regarding atomoxetine treatment. Finally, 149 children were enrolled in this study and completed 12 weeks of atomoxetine treatment, including 56 girls and 93 boys. The demographics and clinical characteristics are summarized in Table 1 . The pre-treatment developmental status of all children included in the study was within the normal range, with an average age of $8.00 \pm 1.29$ years, an average height SDS $(0.19 \pm 0.77)$, weight SDS $(-0.01 \pm 0.35)$, and BMI SDS $(-0.11 \pm 0.46)$.

Table 1. Demographic and clinical characteristics of patients.

\begin{tabular}{cc}
\hline Characteristics & Mean (SD)/N (\%) \\
\hline Age (years, mean (SD)) & $8.9(2.78)$ \\
Gender, boys, N (\%) & $93(62 \%)$ \\
Gender, girls, N (\%) & $56(38 \%)$ \\
ADHD subtype, N (\%) & \\
Predominantly inattentive presentation & $81(54 \%)$ \\
Predominantly hyperactive-impulsive & $5(3 \%)$ \\
presentation & $63(43 \%)$ \\
Combined presentation & \\
Any psychiatric comorbidities & $9(6 \%)$ \\
Tic disorder & $5(3 \%)$ \\
ODD/CD & $4(2 \%)$ \\
Anxiety &
\end{tabular}

Abbreviations: ODD: obsessive compulsive disorder; CD: conduct disorder.

\subsection{Questionnaires Results}

\subsubsection{QCD}

The results of the fully completed patient-reported QCDs at baseline and during the six different treatment time points are summarized in Table 2. All the six different QCD periods and total scores were significantly lower when compared with the baseline $(p<0.001)$. The effect sizes of the atomoxetine treatment, assessed by measuring the difference in the QCD scores between baseline and during the six different treatment time points, are also provided (morning $\mathrm{r}=0.66$, during school $\mathrm{r}=0.57$, after school $\mathrm{r}=0.42$, evening $\mathrm{r}=0.73$, night $r=0.25$, overall behavior $r=0.47$, total score $r=0.83$ ). Our results indicate that the atomoxetine treatment could significantly alleviate behavioral difficulties in primary children with ADHD, especially in the morning prior to school and in the evening. 
Table 2. QCD score.

\begin{tabular}{|c|c|c|c|c|c|c|c|c|}
\hline \multirow{2}{*}{ QCD } & \multicolumn{2}{|c|}{ Baseline } & \multicolumn{2}{|c|}{12 Weeks } & \multirow{2}{*}{$\mathbf{t}$} & \multirow{2}{*}{$p$ Value } & \multirow{2}{*}{ Cohen's $d$} & \multirow{2}{*}{ Effect Size $r$} \\
\hline & Mean & SD & Mean & SD & & & & \\
\hline Morning ** & 5.12 & 1.19 & 7.10 & 1.02 & -17.45 & $<0.001$ & 1.78 & 0.66 \\
\hline During school ** & 5.58 & 1.07 & 7.03 & 0.97 & -14.16 & $<0.001$ & 1.41 & 0.57 \\
\hline After school ** & 6.18 & 1.05 & 7.18 & 1.10 & -8.91 & $<0.001$ & 0.92 & 0.42 \\
\hline Evening $* *$ & 5.75 & 1.00 & 7.88 & 0.98 & -17.23 & $<0.001$ & 2.15 & 0.73 \\
\hline Night $* *$ & 7.53 & 1.08 & 8.08 & 0.96 & -5.86 & $<0.001$ & 0.53 & 0.25 \\
\hline Overall behavior ** & 3.00 & 1.04 & 4.05 & 0.89 & -9.06 & $<0.001$ & 1.08 & 0.47 \\
\hline Total score ${ }^{* *}$ & 33.15 & 2.64 & 41.30 & 2.73 & -22.75 & $<0.001$ & 3.03 & 0.83 \\
\hline
\end{tabular}

** $p<0.001$. Abbreviations: QCD: Questionnaire-Children with Difficulties.

\subsubsection{SNAP-IV}

The SNAP-IV scores are summarized in Table 3. The SNAP-IV inattention mean score was $13.6(\mathrm{SD}=5.8)$ at baseline and $6.1(\mathrm{SD}=4.2)$ at 12 weeks. The SNAP-IV hyperactivity mean score was $11.7(\mathrm{SD}=5.27)$ at baseline and $3.9(\mathrm{SD}=1.59)$ at 12 weeks. SNAP-IV oppositional mean score was $7.9(\mathrm{SD}=4.56)$ at baseline and $1.1(\mathrm{SD}=0.35)$ at 12 weeks. The SNAP-IV total mean score was $33.2(\mathrm{SD}=8.68)$ at baseline and $11.1(\mathrm{SD}=4.38)$ at 12 weeks. The SNAP-IV sub-scores and global scores decreased significantly during the 12 weeks of treatment when compared with the baseline $(p<0.05)$. The effect sizes of the atomoxetine treatment measured the difference in the SNAP-IV scores between baseline and after treatment (inattention $\mathrm{r}=0.59$, hyperactivity /impulsivity $\mathrm{r}=0.7$, oppositional $r=0.72$, total score $r=0.84$ ).

Table 3. SNAP-IV score.

\begin{tabular}{|c|c|c|c|c|c|c|c|c|}
\hline \multirow{2}{*}{ Project } & \multicolumn{2}{|c|}{ Baseline } & \multicolumn{2}{|c|}{12 Weeks } & \multirow{2}{*}{$\mathbf{t}$} & \multirow{2}{*}{$p$ Value } & \multirow{2}{*}{ Cohen's $d$} & \multirow{2}{*}{ Effect Size 1} \\
\hline & Mean & SD & Mean & SD & & & & \\
\hline Inattention ** & 13.60 & 5.80 & 6.10 & 4.20 & 6.18 & $<0.001$ & 1.48 & 0.59 \\
\hline Hyperactivity/impulsivity ${ }^{* *}$ & 11.70 & 5.27 & 3.90 & 1.59 & 4.46 & $<0.001$ & 2.0 & 0.7 \\
\hline Oppositional ** & 7.90 & 4.56 & 1.10 & 0.35 & 5.95 & $<0.001$ & 2.1 & 0.72 \\
\hline Total score ** & 33.20 & 8.68 & 11.10 & 4.38 & 8.50 & $<0.001$ & 3.2 & 0.84 \\
\hline
\end{tabular}

${ }^{* *} p<0.001$. Abbreviations: SNAP-IV: The Swanson, Nolan, and Pelham scale version IV.

\subsubsection{CPRS}

The CPRS scores are summarized in Table 4 . The conduct problems mean score was $0.83(\mathrm{SD}=0.31)$ at baseline and $0.79(\mathrm{SD}=0.29)$ at 12 weeks. The CPRS learning problem mean score was $1.52(\mathrm{SD}=0.32)$ at baseline and $0.59(\mathrm{SD}=0.35)$ at 12 weeks. The CPRS impulse-hyperactivity mean score was $1.19(\mathrm{SD}=0.46)$ at baseline and $0.86(\mathrm{SD}=0.4)$ at 12 weeks, and the hyperactivity index mean score was $1.10(\mathrm{SD}=0.41)$ at baseline and $0.21(\mathrm{SD}=0.18)$ at 12 weeks. The sub-scores for conduct problems, learning problems, impulse-hyperactivity, and hyperactivity index decreased significantly after treatment $(p<0.05)$, while the effect sizes of the atomoxetine treatment were $r=0.06, r=0.81, r=0.35$, and $\mathrm{r}=0.81$, respectively.

\subsection{Effects of Atomoxetine on Children's Development and Serum Growth Parameters}

The serum IGF-1 and IGFBP-3 levels were normal for their sex and age (Supplementary File S1: Detailed information on serum IGF-1 and IGFBP-3 levels at baseline). The height SDS, weight SDS, BMI SDS, and serum growth parameters are illustrated in Table 5. There was a statistically significant difference in weight SDS after treatment when compared with the baseline $(p<0.05)$, but the effect size is slight $(r=0.09)$. However, the height SDS, BMI SDS, and the levels of serum growth parameters did not differ significantly from the baseline after 12 weeks of treatment $(p>0.05)$. 
Table 4. CPRS score.

\begin{tabular}{|c|c|c|c|c|c|c|c|c|}
\hline \multirow{2}{*}{ Project } & \multicolumn{2}{|c|}{ Baseline } & \multicolumn{2}{|c|}{12 Weeks } & \multirow{2}{*}{$\mathbf{t}$} & \multirow{2}{*}{$p$-Value } & \multirow{2}{*}{ Cohen's $d$} & \multirow{2}{*}{ Effect Size } \\
\hline & Mean & SD & Mean & SD & & & & \\
\hline Conduct problems * & 0.83 & 0.31 & 0.79 & 0.29 & 2.49 & 0.017 & 0.13 & 0.06 \\
\hline Learning problems ** & 1.52 & 0.32 & 0.59 & 0.35 & 14.30 & $<0.001$ & 2.77 & 0.81 \\
\hline Psychosomatic disorders & 0.20 & 0.27 & 0.19 & 0.24 & 1.43 & 0.16 & 0.03 & 0.019 \\
\hline Impulse-hyperactivity ** & 1.19 & 0.46 & 0.86 & 0.40 & 6.84 & $<0.001$ & 0.76 & 0.35 \\
\hline Anxiety & 0.38 & 0.30 & 0.31 & 0.21 & 3.09 & 0.06 & 0.27 & 0.13 \\
\hline Hyperactivity index $* *$ & 1.10 & 0.41 & 0.21 & 0.18 & 5.80 & $<0.001$ & 2.8 & 0.81 \\
\hline
\end{tabular}

${ }^{*} p<0.05 ;{ }^{* *} p<0.001$. Abbreviations: CPRS: Conners' Parents Rating Scales.

Table 5. Comparison of height, weight, BMI, and serum growth parameters.

\begin{tabular}{|c|c|c|c|c|c|c|c|c|}
\hline & \multicolumn{2}{|c|}{ Baseline } & \multicolumn{2}{|c|}{12 Weeks } & \multirow{2}{*}{$\mathbf{t}$} & \multirow{2}{*}{$p$} & \multirow{2}{*}{ Cohen's $d$} & \multirow{2}{*}{ Effect Size $r$} \\
\hline & Mean & SD & Mean & SD & & & & \\
\hline Height SDS & 0.19 & 0.77 & 0.08 & 0.80 & 2.80 & 0.08 & 0.14 & 0.06 \\
\hline Weight SDS * & -0.01 & 0.35 & -0.08 & 0.37 & -2.58 & 0.03 & 0.19 & 0.09 \\
\hline BMI SDS & -0.11 & 0.46 & -0.12 & 0.50 & 0.24 & 0.82 & 0.02 & 0.01 \\
\hline IGF-1, ng/mL & 170.43 & 37.27 & 209.71 & 83.53 & -1.20 & 0.28 & 0.60 & 0.27 \\
\hline IGFBP-3, $\mu \mathrm{g} / \mathrm{mL}$ & 4.22 & 0.87 & 4.62 & 0.98 & -7.00 & 0.51 & 0.43 & 0.21 \\
\hline $\mathrm{T} 3, \mathrm{ng} / \mathrm{dL}$ & 115.1 & 10.56 & 114.71 & 14.45 & 0.07 & 0.95 & 0.03 & 0.01 \\
\hline $\mathrm{T} 4, \mathrm{ug} / \mathrm{dL}$ & 8.35 & 1.54 & 8.07 & 0.60 & 0.53 & 0.61 & 0.23 & 0.12 \\
\hline $\mathrm{TSH}, \mathrm{mIU} / \mathrm{mL}$ & 2.64 & 1.46 & 2.44 & 1.00 & 0.54 & 0.60 & 0.15 & 0.07 \\
\hline $\mathrm{TP}, \mathrm{g} / \mathrm{L}$ & 71.76 & 3.73 & 72.42 & 3.55 & -0.44 & 0.67 & 0.18 & 0.09 \\
\hline $\mathrm{ALB}, \mathrm{g} / \mathrm{L}$ & 45.53 & 1.68 & 45.61 & 1.86 & -0.12 & 0.90 & 0.04 & 0.02 \\
\hline $\mathrm{HGB}, \mathrm{g} / \mathrm{L}$ & 133.91 & 5.87 & 137.09 & 6.99 & -1.31 & 0.22 & 0.49 & 0.23 \\
\hline
\end{tabular}

${ }^{*} p<0.05$. Abbreviations: BMI: body mass index; SDs: standard deviation scores; IGF-1: insulin-like growth factor-1; IGFBP-3: insulin-like growth factor-binding protein 3; T3: triiodothyronine, T4: thyroxine; TSH: thyroidstimulating hormone; TP: total protein; ALB: albumin; HGB: hemoglobin.

\subsection{Adverse Reactions Results}

Over the course of the 12 weeks, no severe adverse reactions, such as suicide attempt or suicidal ideation, were reported. Gastrointestinal adverse reactions were reported by $56.38 \%$ of participants during the first three weeks of treatment. The most common gastrointestinal symptom was the loss of appetite or anorexia (35.57\%), followed by constipation $(12.08 \%)$ and nausea and vomiting $(8.72 \%)$. The incidence of neurological side effects was $24.16 \%$, with lethargy (13.42\%) being the most common symptom reported, followed by dizziness $(6.71 \%)$ and emotional instability $(4.03 \%)$. These adverse reactions were effectively alleviated by changing the work and rest time, the medicine administration time, the prandial time, and the diet. Furthermore, the incidence of adverse reactions decreased significantly in the later stage of the treatment, as shown in Table 6.

Table 6. Incidence of adverse reactions, N (\%).

\begin{tabular}{|c|c|c|c|c|c|c|}
\hline Time (Weeks) & $\begin{array}{l}\text { Loss of Appetite } \\
\text { or Anorexia }\end{array}$ & Lethargy & Constipation & $\begin{array}{l}\text { Sickness and } \\
\text { Vomiting }\end{array}$ & Dizziness & $\begin{array}{l}\text { Emotional } \\
\text { Instability }\end{array}$ \\
\hline 3 & $53(36 \%)$ & $20(13 \%)$ & $18(12 \%)$ & $13(8 \%)$ & $10(6 \%)$ & $6(4 \%)$ \\
\hline 6 & $40(27 \%)$ & $15(10 \%)$ & $8(5 \%)$ & 0 & $5(3 \%)$ & 0 \\
\hline 9 & $28(19 \%)$ & $5(3 \%)$ & 0 & 0 & 0 & 0 \\
\hline 12 & $10(7 \%)$ & $5(3 \%)$ & 0 & 0 & 0 & 0 \\
\hline
\end{tabular}

\section{Discussion}

The current prospective study investigated the improvement of behavioral difficulties at different times after a 12-week atomoxetine treatment for primary children diagnosed with ADHD aged between 6 and 12 years, and the possible influence on the growth 
parameters of this treatment. Although behavioral and psychosocial treatments were recommended before pharmacological therapy by the United Kingdom and Germany [50,51], effective behavioral and psychosocial treatments are still more expensive, time-consuming, and less available than pharmacological treatment in medically underserved areas [5]. There are only two drugs, methylphenidate and atomoxetine, approved as the first line to treat ADHD by the China Food and Drug Administration (CFDA, https:/ / www.nmpa.gov.cn, accessed on 16 October 2021). At the same time, clonidine and bupropion were recommended as the second-line medications [36]. As a non-stimulant, atomoxetine works by inhibiting the reuptake of norepinephrine, and effectively increases norepinephrine concentration in the synaptic cleft [1]. To decide upon a first-line pharmacological treatment when choosing between methylphenidate and atomoxetine, the guardians or parents must be fully informed about the adverse reactions at first. This shared decision-making process needs physicians to cooperate with the guardians or parents. In China, the guardians or parents prefer to choose the atomoxetine treatment for the following reasons: (1) fewer adverse reactions on height; (2) they hope the effect of the drug will last throughout the day; (3) the ADHD symptoms are not severe and immediate onset is not needed; (4) concerns about drug abuse $[5,52,53]$. Short stature and growth deficits remain the most common pediatric concerns, and this is mainly presented with growth hormone (GH) deficiency accompanied by lower serum IGF-1 levels [54,55]. However, non-GH deficient short stature disorders, such as idiopathic short stature (ISS) and growth hormone insensitivity (GHI), often present with normal GH when accompanied by lower serum IGF-1 levels [56,57]. Hence, the Growth Hormone Research Society (GRS) and the Chinese official guidelines for diagnosing and treating children with short stature recommended IGF-1 and its main binding protein, IGFBP-3, as valuable biomarkers in assessing growth deficits $[58,59]$. Our prospective study indicated that the use of atomoxetine significantly reduced the symptoms and behavioral difficulties experienced by children who have ADHD. Furthermore, the treatment was generally well tolerated, with few adverse events, and was not associated with growth deficits in the short term.

To the best of our knowledge, this is the first report using the QCD to examine the efficiency of atomoxetine for children aged 6-12 years old with ADHD, in terms of reducing the functional difficulties at different times. The QCD was created by Yamashita, and is widely used in Asian countries, such as China and Japan [60]. The QCD has three key characteristics: the evaluation of life function, the assessment of life function at different periods of the day, and the convenience of use in daily clinical practice [34,35]. Compared with the Child Behavior Checklist (CBCL), which is often used in Western countries, QCD has shown its advantages because it includes only 20 practical and easy-to-understand questions, and only a short time is needed to complete the QCD [61]. The QCD also provides physicians with the necessary information for selecting appropriate drug therapy [34]. In this study, we focused on the two periods that have often been neglected in previous studies of ADHD. The effect of atomoxetine in the morning prior to school $(p<0.001$, $r=0.66)$ and in the evening $(p<0.001, r=0.73)$ was assessed by comparing QCD scores at different times. Our QCD results indicated that atomoxetine could significantly reduce the functional difficulties experienced by ADHD children in these two periods. Family interactions were another neglected point in previous studies of ADHD [29]. Although it is well known that primary school children with ADHD often present with difficulties in the morning prior to school and in the evening [28], previous studies have indicated that parents find it more challenging to take care of ADHD children in the evening. They have reported difficulties in persuading their children to complete their homework and enjoy family time $[62,63]$. Hence, alleviating the core symptoms of ADHD in the morning prior to school and in the evening may effectively solve this problem and reduce parental stress levels. Minimizing parenting stress and improving family interactions are important because they can reduce the risk of adverse outcomes in the long term [64-66]. Consistent with our QCD results, atomoxetine treatment may be a choice in China to alleviate parental stress and to improve family interactions in children with ADHD. This study also compared 
the SNAP-IV scale and CPRS after 12 weeks of treatment with atomoxetine, which further confirmed that atomoxetine is an effective treatment for primary school children with ADHD. The SNAP-IV results showed a significant improvement in the core symptoms of ADHD, while the CPRS results indicated a significant improvement in controlling ADHD symptoms across two different domains, learning problems $(\mathrm{r}=0.81)$ and hyperactivity $(\mathrm{r}=0.86)$. Consistent with previous studies [67-69], our findings indicate that atomoxetine can reduce the core symptoms in primary school children with ADHD.

In this study, the levels of serum growth parameters were closely monitored throughout treatment. These markers have essential roles in promoting children's growth and development [70-72]. In contrast to the BDNF that was lower in newly diagnosed ADHD patients [73], this study found that the serum levels of IGF-1 and IGFBP-3 were within the normal range in newly diagnosed primary school patients with ADHD. These results indirectly confirmed that the secretion and role of endogenous growth hormones were normal in newly diagnosed primary school patients with ADHD. In addition, there was no difference in the levels of IGF-, IGFBP-3, and thyroid function before and after 12 weeks of atomoxetine treatment. A mice model study also showed that atomoxetine did not reduce the expression of the IGF-1 gene [74]. Our serum biochemical results suggested that the atomoxetine did not affect the level of serum growth parameters in children. However, whether the treatment of atomoxetine will affect the levels of serum growth parameters in primary school children with ADHD in the long term remains to be further studied and discussed.

Our study reported no severe adverse reactions, such as suicide attempt or suicidal ideation, throughout treatment. The most significant initial adverse reactions were gastrointestinal symptoms, including the loss of appetite or anorexia, constipation, nausea, and vomiting. These symptoms might be caused by temporary disorders of the central norepinephrine system associated with hunger or satiety [28]. Interestingly, there was no significant difference in the levels of ALB, HGB, and HCT after treatment compared with the baseline. This indicated that, although atomoxetine could cause gastrointestinal adverse reactions, it did not affect the nutritional status of ADHD children. In addition, the height and BMI of children did not lag behind children of the same age without ADHD, and the serum growth parameters were also normal. In our study, despite a significant weight reduction being noted after treatment $(p<0.05)$, the effect size was slight $(\mathrm{r}=0.09)$. A survey by Germinario revealed that the height and weight gradually returned to normal after two years of ADHD treatment. This improvement was more evident for atomoxetine when compared with treatment using methylphenidate [75]. Consistent with our previous results, we speculated that atomoxetine might lead to temporary weight loss due to a loss of appetite. This factor may affect the selection of the short-term pharmacological treatment in China. Based on the guidelines from National Institute for Health and Care Excellence (NICE), temporary weight loss does not require particular caution. If weight loss is of clinical concern, medication should be taken either during or after meals rather than before meals, and additional meals or snacks early in the morning or late in the evening are also suggested [51].

\section{Limitations}

Our study has some limitations that have to be acknowledged. First of all, all enrolled patients were from a single center, so a selection bias could not be entirely ruled out. Secondly, although all questionnaires were completed by parents/guardians electronically at the clinical department and there were no missing data, the expectations of parents/guardians and their insufficient training by the clinicians might have introduced a positive bias into our findings. Furthermore, although all enrolled patients were newly diagnosed with ADHD, this study did not compare the use of atomoxetine with a placebo. Therefore, the symptom improvement noted in ADHD children could have resulted from natural growth and development. Finally, the small number of patients enrolled in this study may affect the generalizability of the research findings. 


\section{Conclusions}

In summary, this study determined that atomoxetine positively affects behavioral difficulties in primary school children with ADHD and confirmed that atomoxetine would not affect growth development in the short term. In addition, our study was the first one using the QCD to prove that atomoxetine treatment can significantly reduce the functional difficulties experienced by ADHD children in the morning prior to school and in the evening. Atomoxetine may be a good choice in China to alleviate the stress of parents/guardians, and to improve family interactions with primary school children with ADHD. Moreover, our study indicated that the serum levels of IGF-1 and IGFBP-3 were within the normal range in newly diagnosed ADHD patients, and that atomoxetine will not affect the serum concentration of growth parameters in the short-term.

Supplementary Materials: The following supporting information can be downloaded at: https:// www.mdpi.com/article/10.3390/children9020212/s1, Supplementary File S1: Detailed information on serum IGF-1 and IGFBP-3 levels at baseline [76].

Author Contributions: Conceptualization, Y.L. and C.S.; methodology, H.M. and R.X.; software, T.L. and Z.C.; formal analysis, H.M., R.X., T.L. and Z.C.; investigation, H.M.; resources, H.M., R.X., Y.L. and C.S.; data curation, H.M, R.X., T.L. and Z.C.; writing-original draft preparation, H.M.; writing-review and editing, H.M. and R.X.; supervision, Y.L. and C.S. All authors have read and agreed to the published version of the manuscript.

Funding: This research received no external funding.

Institutional Review Board Statement: The study was conducted in accordance with the Declaration of Helsinki, and approved by the The Research Ethics Committees of the Affiliated Hospital of Jiangnan University (Wuxi, China) (No.LS2019047, approval date: 10 December 2019).

Informed Consent Statement: Informed consent was obtained from all subjects involved in the study.

Data Availability Statement: The data used to support the conclusions of this article are available from the corresponding authors upon request.

Acknowledgments: The authors would like to thank all parents/guardians/children who took part in the study. This work was supported by The Jiangnan University Affiliated Hospital.

Conflicts of Interest: The authors declared that they have no conflict of interest.

\section{Abbreviations}

$\begin{array}{ll}\text { ADHD } & \text { Attention-deficit/hyperactivity disorder; } \\ \text { IGF-1 } & \text { Insulin-like growth factor-1; } \\ \text { IGFBP-3 } & \text { Insulin-like growth factor-binding protein 3; } \\ \text { SDs } & \text { Standard deviation scores; } \\ \text { GH } & \text { Growth hormone; } \\ \text { DSM-V } & \text { Diagnostic and Statistical Manual of Mental Disorders, Fifth Edition; } \\ \text { QCD } & \text { Questionnaire-Children with Difficulties; } \\ \text { SNAP-IV } & \text { The Swanson, Nolan, and Pelham scale version IV; } \\ \text { CPRS } & \text { Conners' Parents Rating Scales; }\end{array}$

\section{References}

1. Drechsler, R.; Brem, S.; Brandeis, D.; Grünblatt, E.; Berger, G.; Walitza, S. ADHD: Current Concepts and Treatments in Children and Adolescents. Neuropediatrics 2020, 51, 315-335. [CrossRef] [PubMed]

2. Chang, J.G.; Cimino, F.M.; Gossa, W. ADHD in Children: Common Questions and Answers. Am. Fam. Physician 2020, 102, 592-602.

3. Banaschewski, T.; Becker, K.; Döpfner, M.; Holtmann, M.; Rösler, M.; Romanos, M. Attention-Deficit/Hyperactivity Disorder. Dtsch. Arztebl. Int. 2017, 114, 149-159. [CrossRef] [PubMed]

4. Cortese, S. Pharmacologic Treatment of Attention Deficit-Hyperactivity Disorder. N. Engl. J. Med. 2020, 383, 1050-1056. [CrossRef] [PubMed] 
5. Caye, A.; Swanson, J.M.; Coghill, D.; Rohde, L.A. Treatment strategies for ADHD: An evidence-based guide to select optimal treatment. Mol. Psychiatry 2018, 24, 390-408. [CrossRef]

6. Bolea-Alamañac, B.; Nutt, D.J.; Adamou, M.; Asherson, P.; Bazire, S.; Coghill, D.; Heal, D.; Müller, U.; Nash, J.; Santosh, P.; et al Evidence-based guidelines for the pharmacological management of attention deficit hyperactivity disorder: Update on recommendations from the British Association for Psychopharmacology. J. Psychopharmacol. 2014, 28, 179-203. [CrossRef]

7. Pliszka, S. Practice parameter for the assessment and treatment of children and adolescents with attention-deficit/hyperactivity disorder. J. Am. Acad. Child Adolesc. Psychiatry 2007, 46, 894-921. [CrossRef]

8. Wolraich, M.L.; Hagan, J.F.; Allan, C.; Chan, E.; Davison, D.; Earls, M.; Evans, S.W.; Flinn, S.K.; Froehlich, T.; Frost, J.; et al. Clinical Practice Guideline for the Diagnosis, Evaluation, and Treatment of Attention-Deficit/Hyperactivity Disorder in Children and Adolescents. Pediatrics 2019, 144, e20192528. [CrossRef]

9. Fedder, D.; Patel, H.; Saadabadi, A. Atomoxetine. In StatPearls; StatPearls Publishing LLC: Treasure Island, FL, USA, 2021.

10. Kweon, K.; Yoon, J.S.; Park, K.J.; Kim, S.-O.; Choi, J.-H.; Kim, H.-W. Effects of Atomoxetine on Height and Weight in Korean Children and Adolescents with Attention-Deficit/Hyperactivity Disorder: A Retrospective Chart Review. Psychiatry Investig. 2018, 15, 649-654. [CrossRef]

11. Corona, J.C.; Carreón-Trujillo, S.; González-Pérez, R.; Gómez-Bautista, D.; Vázquez-González, D.; Salazar-García, M. Atomoxetine produces oxidative stress and alters mitochondrial function in human neuron-like cells. Sci. Rep. 2019, 9, 13011. [CrossRef]

12. Yu, G.; Li, G.-F.; Markowitz, J.S. Atomoxetine: A Review of Its Pharmacokinetics and Pharmacogenomics Relative to Drug Disposition. J. Child Adolesc. Psychopharmacol. 2016, 26, 314-326. [CrossRef] [PubMed]

13. Hinshaw, S.P. Attention Deficit Hyperactivity Disorder (ADHD): Controversy, Developmental Mechanisms, and Multiple Levels of Analysis. Annu. Rev. Clin. Psychol. 2018, 14, 291-316. [CrossRef]

14. Schuch, V.; Utsumi, D.A.; Costa, T.V.M.M.; Kulikowski, L.D.; Muszkat, M. Attention Deficit Hyperactivity Disorder in the Light of the Epigenetic Paradigm. Front. Psychiatry 2015, 6, 126. [CrossRef]

15. Khan, N.; Smith, M.T. Neurotrophins and Neuropathic Pain: Role in Pathobiology. Molecules 2015, 20, 10657-10688. [CrossRef] [PubMed]

16. Tonoli, C.; Heyman, E.; Roelands, B.; Buyse, L.; Piacentini, F.; Berthoin, S.; Bailey, S.; Pattyn, N.; Meeusen, R. BDNF, IGF-I, Glucose and Insulin during Continuous and Interval Exercise in Type 1 Diabetes. Int. J. Sports Med. 2015, 36, 955-959. [CrossRef] [PubMed]

17. Chang, J.P.-C.; Mondelli, V.; Satyanarayanan, S.K.; Chiang, Y.-J.; Chen, H.-T.; Su, K.-P.; Pariante, C.M. Cortisol, inflammatory biomarkers and neurotrophins in children and adolescents with attention deficit hyperactivity disorder (ADHD) in Taiwan. Brain Behav. Immun. 2020, 88, 105-113. [CrossRef]

18. Meng, W.-D.; Sun, S.-J.; Yang, J.; Chu, R.-X.; Tu, W.; Liu, Q. Elevated Serum Brain-Derived Neurotrophic Factor (BDNF) but not BDNF Gene Val66Met Polymorphism Is Associated with Autism Spectrum Disorders. Mol. Neurobiol. 2017, 54, 1167-1172. [CrossRef]

19. Yan, J.; Herzog, J.W.; Tsang, K.; Brennan, C.A.; Bower, M.A.; Garrett, W.S.; Sartor, B.R.; Aliprantis, A.O.; Charles, J.F. Gut microbiota induce IGF-1 and promote bone formation and growth. Proc. Natl. Acad. Sci. USA 2016, 113, E7554-E7563. [CrossRef]

20. Yoshida, T.; Delafontaine, P. Mechanisms of IGF-1-Mediated Regulation of Skeletal Muscle Hypertrophy and Atrophy. Cells 2020, 9, 1970. [CrossRef]

21. Bakker, N.E.; van Doorn, J.; Renes, J.S.; Donker, G.H.; Hokken-Koelega, A.C.S. IGF-1 Levels, Complex Formation, and IGF Bioactivity in Growth Hormone-Treated Children With Prader-Willi Syndrome. J. Clin. Endocrinol. Metab. 2015, 100, 3041-3049. [CrossRef]

22. Jain, N.; Tripathi, T.; Gupta, S.K.; Rai, P.; Kanase, A.; Kalra, S. Serum IGF-1, IGFBP-3 and their ratio: Potential biochemical growth maturity indicators. Prog. Orthod. 2017, 18, 11. [CrossRef] [PubMed]

23. Sinha, M.; Tripathi, T.; Rai, P.; Gupta, S.K. Serum and urine insulin-like growth factor-1 as biochemical growth maturity indicators Am. J. Orthod. Dentofac. Orthop. 2016, 150, 1020-1027. [CrossRef]

24. Sun, M.; Yan, W.; Zhao, Q.; Ji, B.; Ban, B.; Zhang, M. Association Between Serum Calcium and Phosphorus Levels and Insulin-Like Growth Factor-1 in Chinese Children and Adolescents with Short Stature. Int. J. Gen. Med. 2020, 13, 1167-1173. [CrossRef]

25. Bereket, A.; Turan, S.; Karaman, M.G.; Haklar, G.; Ozbay, F.; Yazgan, M.Y. Height, Weight, IGF-I, IGFBP-3 and Thyroid Functions in Prepubertal Children with Attention Deficit Hyperactivity Disorder: Effect of Methylphenidate Treatment. Horm. Res. Paediatr. 2005, 63, 159-164. [CrossRef] [PubMed]

26. Kim, W.J.; Bang, Y.R.; Kang, J.W.; Yoo, J.H.; Kim, S.H.; Park, J.H. Preliminary Investigation of Association between Methylphenidate and Serum Growth Markers in Children with Attention-Deficit/Hyperactivity Disorder: A Cross-Sectional Case-Control Study. Soa Chongsonyon Chongsin Uihak 2020, 31, 154-160. [CrossRef]

27. Toren, P.; Silbergeld, A.; Eldar, S.; Laor, N.; Wolmer, L.; Koren, S.; Weitz, R.; Inbar, D.; Reiss, A.; Eshet, R.; et al. Lack of Effect of Methylphenidate on Serum Growth Hormone (GH), GH-Binding Protein, and Insulin-like Growth Factor I. Clin. Neuropharmacol. 1997, 20, 264-269. [CrossRef]

28. Wilens, T.E.; Faraone, S.V.; Hammerness, P.G.; Pliszka, S.R.; Uchida, C.L.; DeSousa, N.J.; Sallee, F.R.; Incledon, B.; Newcorn, J.H Clinically Meaningful Improvements in Early Morning and Late Afternoon/Evening Functional Impairment in Children with ADHD Treated with Delayed-Release and Extended-Release Methylphenidate. J. Atten. Disord. 2022, 26, 696-705. [CrossRef] [PubMed] 
29. Faraone, S.V.; DeSousa, N.J.; Komolova, M.; Sallee, F.R.; Incledon, B.; Wilens, T.E. Functional Impairment in Youth With ADHD: Normative Data and Norm-Referenced Cutoff Points for the Before School Functioning Questionnaire and the Parent Rating of Evening and Morning Behavior Scale, Revised. J. Clin. Psychiatry 2019, 81, 12902. [CrossRef] [PubMed]

30. Liu, T.; Gobburu, J.V.; Po, M.D.; McLean, A.; DeSousa, N.J.; Sallee, F.R.; Incledon, B. Pharmacokinetics of HLD200, a DelayedRelease and Extended-Release Methylphenidate: Evaluation of Dose Proportionality, Food Effect, Multiple-Dose Modeling, and Comparative Bioavailability with Immediate-Release Methylphenidate in Healthy Adults. J. Child Adolesc. Psychopharmacol. 2019, 29, 181-191. [CrossRef]

31. Pliszka, S.R.; Wilens, T.E.; Bostrom, S.; Arnold, V.K.; Marraffino, A.; Cutler, A.J.; López, F.A.; DeSousa, N.J.; Sallee, F.R.; Incledon, B.; et al. Efficacy and Safety of HLD200, Delayed-Release and Extended-Release Methylphenidate, in Children with Attention-Deficit/Hyperactivity Disorder. J. Child Adolesc. Psychopharmacol. 2017, 27, 474-482. [CrossRef]

32. Childress, A.C.; Cutler, A.J.; Marraffino, A.; McDonnell, M.A.; Turnbow, J.M.; Brams, M.; DeSousa, N.J.; Incledon, B.; Sallee, F.R.; Wigal, S.B. A Randomized, Double-Blind, Placebo-Controlled Study of HLD200, a Delayed-Release and Extended-Release Methylphenidate, in Children with Attention-Deficit/Hyperactivity Disorder: An Evaluation of Safety and Efficacy Throughout the Day and Across Settings. J. Child Adolesc. Psychopharmacol. 2020, 30, 2-14. [CrossRef]

33. Kelsey, D.K.; Sumner, C.R.; Casat, C.D.; Coury, D.L.; Quintana, H.; Saylor, K.E.; Sutton, V.K.; Gonzales, J.; Malcolm, S.K.; Schuh, K.J.; et al. Once-Daily Atomoxetine Treatment for Children With Attention-Deficit/Hyperactivity Disorder, Including an Assessment of Evening and Morning Behavior: A Double-Blind, Placebo-Controlled Trial. Pediatrics 2004, 114, e1-e8. [CrossRef] [PubMed]

34. Usami, M.; Sasayama, D.; Sugiyama, N.; Hosogane, N.; Kim, S.-Y.; Yamashita, Y.; Kodaira, M.; Watanabe, K.; Iwadare, Y.; Sawa, T.; et al. The reliability and validity of the Questionnaire-Children with Difficulties (QCD). Child Adolesc. Psychiatry Ment. Heal. 2013, 7, 11. [CrossRef]

35. Zheng, Y.; Du, Y.; Su, L.Y.; Zhang, Y.; Yuan, Z.; Chen, Y.; Liu, Q.Q.; Ke, X.Y. Reliability and validity of the Chinese version of Questionnaire-Children with Difficulties for Chinese children or adolescents with attention-deficit/hyperactivity disorder: A cross-sectional survey. Neuropsychiatr. Dis. Treat. 2018, 14, 2181-2190. [CrossRef] [PubMed]

36. Liu, Q.; Zhen, Y. Interpretation of the second edition of the guidelines for the treatment of attention deficit hyperactivity disorder in china. Chin. J. Psychiatry 2016, 49, 132-135.

37. Ke, X.; Du, Y.; Zheng, Y.; Su, L.; Chen, Y.; Zhang, Y.; Chen, K.; Cheng, Y.; Chen, W. Risk factors for the difficulties in general activities across the day in Chinese children and adolescents with attention-deficit/hyperactivity disorder. Neuropsychiatr. Dis. Treat. 2019, 15, 157-166. [CrossRef] [PubMed]

38. Bussing, R.; Fernandez, M.; Harwood, M.; Hou, W.; Garvan, C.W.; Eyberg, S.M.; Swanson, J.M. Parent and teacher SNAP-IV ratings of attention deficit hyperactivity disorder symptoms: Psychometric properties and normative ratings from a school district sample. Assessment 2008, 15, 317-328. [CrossRef]

39. Gau, S.S.-F.; Shang, C.-Y.; Liu, S.-K.; Lin, C.-H.; Swanson, J.M.; Liu, Y.-C.; Tu, C.-L. Psychometric properties of the Chinese version of the Swanson, Nolan, and Pelham, version IV scale-Parent form. Int. J. Methods Psychiatr. Res. 2008, 17, 35-44. [CrossRef] [PubMed]

40. Gau, S.S.-F.; Lin, C.-H.; Hu, F.-C.; Shang, C.-Y.; Swanson, J.M.; Liu, Y.-C.; Liu, S.-K. Psychometric Properties of the Chinese Version of the Swanson, Nolan, and Pelham, Version IV Scale-Teacher Form. J. Pediatr. Psychol. 2009, 34, 850-861. [CrossRef] [PubMed]

41. Conners, C.K.; Sitarenios, G.; Parker, J.D.; Epstein, J.N. The revised Conners' Parent Rating Scale (CPRS-R): Factor structure, reliability, and criterion validity. J. Abnorm. Child Psychol. 1998, 26, 257-268. [CrossRef]

42. Chang, L.-Y.; Wang, M.-Y.; Tsai, P.-S. Diagnostic Accuracy of Rating Scales for Attention-Deficit/Hyperactivity Disorder: A Meta-analysis. Pediatrics 2016, 137, e20152749. [CrossRef] [PubMed]

43. Shuai, L.; Daley, D.; Wang, Y.F.; Zhang, J.S.; Kong, Y.T.; Tan, X.; Ji, N. Executive Function Training for Children with Attention Deficit Hyperactivity Disorder. Chin. Med. J. 2017, 130, 549-558. [CrossRef] [PubMed]

44. Pozzi, M.; Carnovale, C.; Peeters, G.G.; Gentili, M.; Antoniazzi, S.; Radice, S.; Clementi, E.; Nobile, M. Adverse drug events related to mood and emotion in paediatric patients treated for ADHD: A meta-analysis. J. Affect. Disord. 2018, 238, 161-178. [CrossRef] [PubMed]

45. Clavenna, A.; Bonati, M. Pediatric pharmacoepidemiology—Safety and effectiveness of medicines for ADHD. Expert Opin. Drug Saf. 2017, 16, 1335-1345. [CrossRef] [PubMed]

46. Ekhart, C.; Vries, T.; Hunsel, F.V. Psychiatric adverse drug reactions in the paediatric population. Arch. Dis. Child. 2020, 105, 749-755. [CrossRef]

47. Pozzi, M.; Carnovale, C.; Mazhar, F.; Peeters, G.; Gentili, M.; Nobile, M.; Radice, S.; Clementi, E. Adverse Drug Reactions Related to Mood and Emotion in Pediatric Patients Treated for Attention Deficit/Hyperactivity Disorder: A Comparative Analysis of the US Food and Drug Administration Adverse Event Reporting System Database. J. Clin. Psychopharmacol. 2019, 39, 386-392. [CrossRef] [PubMed]

48. Aagaard, L.; Hansen, E.H. The occurrence of adverse drug reactions reported for attention deficit hyperactivity disorder (ADHD) medications in the pediatric population: A qualitative review of empirical studies. Neuropsychiatr. Dis. Treat. 2011, 7, 729-744. [CrossRef] [PubMed] 
49. De Sanctis, V.; Soliman, A.T.; Candini, G.; Yassin, M.; Raiola, G.; Galati, M.C.; Elalaily, R.; Elsedfy, H.; Skordis, N.; Garofalo, P.; et al. Insulin-like Growth Factor-1 (IGF-1): Demographic, Clinical and Laboratory Data in 120 Consecutive Adult Patients with Thalassaemia Major. Mediterr. J. Hematol. Infect. Dis. 2014, 6, e2014074. [CrossRef] [PubMed]

50. Medical, A.o.t.S. and S.i.G. (AWMF). The German Guidelines for the Diagnosis and Management of ADHD in Children, Adolescents and Adults. 2018. Available online: https://adhd-institute.com/disease-management/guidelines/german-guidelines (accessed on 3 January 2022).

51. National Institute for Health and Care Excellence. National Institute for Health and Care Excellence: Clinical Guidelines, in Attention Deficit Hyperactivity Disorder: Diagnosis and Management; National Institute for Health and Care Excellence: London, UK, 2018.

52. Shellenberg, T.P.; Stoops, W.W.; Lile, J.A.; Rush, C.R. An update on the clinical pharmacology of methylphenidate: Therapeutic efficacy, abuse potential and future considerations. Expert Rev. Clin. Pharmacol. 2020, 13, 825-833. [CrossRef]

53. Carucci, S.; Balia, C.; Gagliano, A.; Lampis, A.; Buitelaar, J.K.; Danckaerts, M.; Dittmann, R.W.; Garas, P.; Hollis, C.; Inglis, S.; et al. Long term methylphenidate exposure and growth in children and adolescents with ADHD. A systematic review and metaanalysis. Neurosci. Biobehav. Rev. 2021, 120, 509-525. [CrossRef]

54. Grimberg, A.; DiVall, S.A.; Polychronakos, C.; Allen, D.B.; Cohen, L.E.; Quintos, J.B.; Rossi, W.C.; Feudtner, C.; Murad, M.H.; on behalf of the Drug and Therapeutics Committee and Ethics Committee of the Pediatric Endocrine Society. Guidelines for Growth Hormone and Insulin-Like Growth Factor-I Treatment in Children and Adolescents: Growth Hormone Deficiency, Idiopathic Short Stature, and Primary Insulin-Like Growth Factor-I Deficiency. Horm. Res. Paediatr. 2016, 86, 361-397. [PubMed]

55. Collett-Solberg, P.F.; Jorge, A.A.; Boguszewski, M.C.; Miller, B.S.; Choong, C.S.Y.; Cohen, P.; Hoffman, A.R.; Luo, X.; Radovick, S.; Saenger, P. Growth hormone therapy in children; research and practice-A review. Growth Horm. IGF Res. 2018, 44, 20-32. [CrossRef] [PubMed]

56. Anwar, G.M.; Kandeel, W.A.; Mandour, I.A.; Kamal, A.N. Study of primary IGF-1 deficiency in Egyptian children with idiopathic short stature. Horm. Res. Paediatr. 2013, 79, 277-282. [CrossRef] [PubMed]

57. Hwa, V.; Fujimoto, M.; Zhu, G.; Gao, W.; Foley, C.; Kumbaji, M.; Rosenfeld, R.G. Genetic causes of growth hormone insensitivity beyond GHR. Rev. Endocr. Metab. Disord. 2021, 22, 43-58. [CrossRef]

58. Shen, Y.; Wang, D. Guidelines for the diagnosis and treatment of short children. Chin. J. Pediatrics 2008, 6, 428-430.

59. Collett-Solberg, P.F.; Ambler, G.; Backeljauw, P.F.; Bidlingmaier, M.; Biller, B.M.; Boguszewski, M.C.; Cheung, P.T.; Choong, C.S.Y.; Cohen, L.E.; Cohen, P.; et al. Diagnosis, Genetics, and Therapy of Short Stature in Children: A Growth Hormone Research Society International Perspective. Horm. Res. Paediatr. 2019, 92, 1-14. [CrossRef]

60. Goto, T.; Yamashita, Y.; Usami, M.; Takahashi, M.; Saito, K. A tool for the assessment of daily life functioning of children “Questionnaire-children with Difficulties (QCD. Jpn. J. Pediatrics 2011, 64, 99-106.

61. Wehmeier, P.M.; Schacht, A.; Dittmann, R.W.; Döpfner, M. Global impression of perceived difficulties in children and adolescents with attention-deficit/hyperactivity disorder: Reliability and validity of a new instrument assessing perceived difficulties from a patient, parent and physician perspective over the day. Child Adolesc. Psychiatry Ment. Heal. 2008, 2, 10.

62. Sasaki, Y.; Usami, M.; Sasayama, D.; Okada, T.; Iwadare, Y.; Watanabe, K.; Ushijima, H.; Tanaka, T.; Harada, M.; Tanaka, H.; et al. Concerns Expressed by Parents of Children with Pervasive Developmental Disorders for Different Time Periods of the Day: A Case-Control Study. PLoS ONE 2015, 10, e0124692.

63. Usami, M.; Okada, T.; Sasayama, D.; Iwadare, Y.; Watanabe, K.; Ushijima, H.; Kodaira, M.; Sugiyama, N.; Sawa, T.; Saito, K. What time periods of the day are concerning for parents of children with attention deficit hyperactivity disorder? PLOS ONE 2013, 8, e79806. [CrossRef]

64. Hoza, B. Peer functioning in children with ADHD. Ambul. Pediatr. 2007, 7, 101-106. [CrossRef] [PubMed]

65. Muñoz-Silva, A.; Urbano, R.L.; Sanchez-Garcia, M.; Carmona-Márquez, J. Child/Adolescent's ADHD and Parenting Stress: The Mediating Role of Family Impact and Conduct Problems. Front. Psychol. 2017, 8, 2252. [CrossRef] [PubMed]

66. Gordon, C.T.; Hinshaw, S.P. Parenting Stress as a Mediator Between Childhood ADHD and Early Adult Female Outcomes. J. Clin. Child Adolesc. Psychol. 2017, 46, 588-599. [CrossRef] [PubMed]

67. Schwartz, S.; Correll, C.U. Efficacy and Safety of Atomoxetine in Children and Adolescents With Attention-Deficit/Hyperactivity Disorder: Results From a Comprehensive Meta-Analysis and Metaregression. J. Am. Acad. Child Adolesc. Psychiatry 2014, 53, 174-187. [CrossRef] [PubMed]

68. Goto, T.; Hirata, Y.; Takita, Y.; Trzepacz, P.T.; Allen, A.J.; Song, D.-H.; Gau, S.S.-F.; Ichikawa, H.; Takahashi, M. Efficacy and Safety of Atomoxetine Hydrochloride in Asian Adults With ADHD. J. Atten. Disord. 2017, 21, 100-109. [CrossRef] [PubMed]

69. Upadhyaya, H.; Kratochvil, C.; Ghuman, J.; Camporeale, A.; Lipsius, S.; D'Souza, D.; Tanaka, Y. Efficacy and Safety Extrapolation Analyses for Atomoxetine in Young Children with Attention-Deficit/Hyperactivity Disorder. J. Child Adolesc. Psychopharmacol. 2015, 25, 799-809. [CrossRef]

70. Zhou, P.; Lv, Q. The effects of growth hormones on the growth velocities and serum index expressions in short stature children. Am. J. Transl. Res. 2021, 13, 8421-8426. [PubMed]

71. Upners, E.N.; Ljubicic, M.L.; Busch, A.S.; Fischer, M.B.; Almstrup, K.; Petersen, J.H.; Jensen, R.B.; Hagen, C.P.; Juul, A. Dynamic Changes in Serum IGF-I and Growth During Infancy: Associations to Body Fat, Target Height, and PAPPA2 Genotype. J. Clin. Endocrinol. Metab. 2021, 107, 219-229. [CrossRef]

72. Nilsson, M.; Fagman, H. Development of the thyroid gland. Development 2017, 144, 2123-2140. [CrossRef] 
73. Cubero-Millán, I.; Ruiz-Ramos, M.-J.; Molina-Carballo, A.; Martínez-Serrano, S.; Fernández-López, L.; Machado-Casas, I.; Tortosa-Pinto, P.; Ruiz-López, A.; Luna-Del-Castillo, J.-D.; Uberos, J.; et al. BDNF concentrations and daily fluctuations differ among ADHD children and respond differently to methylphenidate with no relationship with depressive symptomatology. Psychopharmacology 2017, 234, 267-279. [CrossRef]

74. Jesinkey, S.R.; Korrapati, M.C.; Rasbach, K.A.; Beeson, C.C.; Schnellmann, R.G. Atomoxetine prevents dexamethasone-induced skeletal muscle atrophy in mice. J. Pharmacol. Exp. Ther. 2014, 351, 663-673. [CrossRef] [PubMed]

75. Germinario, E.A.P.; Arcieri, R.; Bonati, M.; Zuddas, A.; Masi, G.; Vella, S.; Chiarotti, F.; Panei, A.T.I.A.R.P. Attentiondeficit/hyperactivity disorder drugs and growth: An Italian prospective observational study. J. Child Adolesc. Psychopharmacol. 2013, 23, 440-447. [CrossRef] [PubMed]

76. Xu, S.; Gu, X.; Pan, H.; Zhu, H.; Gong, F.; Li, Y.; Xing, Y. A study of normal reference values for serum insulin growth factor-1 and insulin factor-binding protein-3 in children and adolescents. Clin. Pediatr. 2009, 27, 1105-1110. 